\title{
Protective effects of silymarin on methotrexate-induced damages in rat testes
}

\author{
Turan Yaman ${ }^{1 *}$, Ahmet Uyar², Mehmet Salih Kaya ${ }^{3}$, Ömer Faruk Keles ${ }^{1}$, Baris Atalay Uslu ${ }^{4}$, \\ Zabit Yener $^{1}$
}

\begin{abstract}
${ }^{1}$ Department of Pathology, Faculty of Veterinary Medicine, Yüzüncü Yll University, Van, Turkey, ${ }^{2}$ Department of Pathology, Faculty of Veterinary Medicine Mustafa Kemal University, ${ }^{3}$ Depatment of Physiology, Faculty of Medicine, Ankara Ylldirlm Beyazit University, Ankara, Turkey, ${ }^{4}$ Depatment of Reproduction and Artificial Insemination, Faculty of Veterinary Medicine, Cumhuriyet University, Sivas, Turkey
\end{abstract}

\begin{abstract}
The present study aimed to investigate the protective effects of silymarin (SMN), an antioxidant, on methotrexate (MTX)-induced damage in rat testes. Thirty-two Wistar albino rats were divided into four groups $(n=8)$ : control, MTX (20 mg/kg, i.p. on days 1 and 5), SMN (200 mg/kg, orally), and MTX + SMN (20 mg/kg, i.p. on days 1 and 5 and SMN $200 \mathrm{mg} / \mathrm{kg}$ orally) groups. At the end of the 6-week trial period, histopathological, immunohistochemical, biochemical, and spermatological analyses were performed on testes tissues. Histopathologically, MTX-induced damage, including depletion of germ cell and loos of spermatozoa, was significantly improved with SMN treatment. Immunohistochemically, the immunoreactivity of glutathione peroxidase 1 (GPx1) and manganese superoxide dismutase 2 (SOD2) were detected more intensely in the MTX + SMN group than in the MTX group. Biochemical examinations revealed that SMN supplementation decreased the lipid peroxidation and increased enzymatic antioxidants in the SMN-treated rats. Spermatologically, significant differences were found in the density, motility, dead-to-live sperm ratio, and abnormal sperm rate in the MTX + SMN group compared to the MTX group. In conclusion, SMN seems to have protective effects as an antioxidant against MTX-induced damage in rat testes.
\end{abstract}

Keywords: Silymarin/effects. Methotrexate/Testes/induced damages. GPx1. SOD2. Pathology.

\section{INTRODUCTION}

Methotrexate (MTX) is a folic acid antagonist that has anti-neoplastic characteristics (Thomson et al., 2012). It has been used to treat rheumatic diseases since the 1950s (Gogus, 2001) and has been used to treat acute lymphoblastic leukemia; lymphoma; osteosarcoma; and breast, head and neck cancers; as well as non-malignant diseases like psoriasis and rheumatic arthritis. MTX has toxic effects, particularly on rapidly proliferating cells, such as gastrointestinal epithelial and bone marrow cells (Sargin et al., 2009), and studies have reported that MTX causes damage in certain organs, such as the kidneys (Sargin et al., 2009), liver (Asci, Ozer, 2011), and intestines (Vardi et al., 2008).

\footnotetext{
*Correspondence: T. Yaman. Department of Pathology Faculty of Veterinary Medicine, Yüzüncü Yıl University, 65090 Zevve Kampüsü, Van, Turkey. Tel:+90 4322251128. E-mail: turanyaman@yyu.edu.tr
}

Testicular damage is the most important potential side effect of MTX (Yuluğ et al., 2013) and can lead to infertility (Moris et al., 1993). Previous studies have reported damage in the seminiferous tubules of the testes, decreased sperm count, and sperm DNA damage after MTX administration (Padmanabhan et al., 2009; Yuluğ et al., 2013). Additionally, MTX causes defective oogenesis and spermatogenesis (Vardi et al., 2009). Oxidative stress has an important effect in the pathogenesis of MTXinduced testicular damage (Armagan et al., 2008). It leads to damage to the structure of the testes and germ cells (Atessahin, Şahna, Türk, 2006). Therefore, it is important to reduce cellular oxidative stress in patients receiving MTX (Vardi et al., 2009).

In several studies, polyphenolic compounds have shown to be potential antioxidants useful for the treatment and prevention of oxidative stress (Uyar, Yener, Dogan, 2016; Yaman, Yener, Celik, 2016). Antioxidant agents are used to minimize the adverse effects of anticancer drugs 
on the testicles (Muslimovic et al., 2009; Padmanabhan et al., 2009). These agents deactivate free radicals by sending electrons to attack them, and antioxidants offer protection from free radicals and lipid peroxidation (Valavanidis et al., 2006) by inhibiting or delaying cellular damage with their free radical-scavenging effect (Halliwell, 1995). Prior studies conducted to identify ways in which to prevent the testicular damage caused by MTX have reported that the damage is largely prevented by antioxidants like vitamin E, L-carnitine (Bükücü, 2013), vitamin C (Sayilmaz, 2015), and caffeic acid phenethyl ester (Armagan et al., 2008).

Silymarin (SMN) is a natural polyphenolic compound isolated from the seeds of Silybum marianum (milk thistle). SMN can inhibit both free radicals and reactive oxygen species (ROS). It reacts with the latter and converts them into compounds with decreased reactivity and toxicity. It also potentiates the effects of physiological antioxidants, such as glutathione and superoxide dismutase (SOD) (Nencini, Giorgi, Micheli, 2007; Moshtaghion et al., 2013). Previous studies suggest that SMN could protect tissues against toxicity from the most commonly used anticancer agents (Rašković et al., 2011).

The present study aimed to investigate the antioxidant properties and protective role of SMN against MTX-induced testicular damage. We also demonstrated the immunolocalization of GPx1 and SOD2 in testicular tissue.

\section{MATERIAL AND METHODS}

\section{Chemicals}

The chemicals used in this study were supplied by Sigma Chemical Co. (St. Louis, MO, USA). Kits for antioxidant enzyme analysis were provided by Randox Laboratories Ltd. SMN powder was purchased from Sigma (S0292, USA). MTX (Koçak Farma, Tekirdağ, Turkey) was purchased from a local pharmacy.

\section{Animals}

Thirty two Wistar albino male rats aged 4-6 months and weighing 200-300 g were provided by the Experimental Animal Research Center, Dicle University. The animals were housed at $20 \pm 2{ }^{\circ} \mathrm{C}$ under daily light/ dark cycle. They were kept in stainless cages and fed a wheat and soybean-meal-based diet. Water and feed were provided ad libitum. Ethics regulations were followed in accordance with the national and institutional guidelines for the protection of animal welfare during the experiments. This study was approved by the ethics committee of Dicle University-(Protocol number: 2015/7).

\section{Experimental model} $(\mathrm{n}=8)$

The rats were randomly divided into four groups

Control group (C): Rats in this group received 0.9\% $\mathrm{NaCl}(1 \mathrm{ml} / \mathrm{kg}$, orally). Those in the MTX group received MTX $(20 \mathrm{mg} / \mathrm{kg}$, intraperitoneally [i.p.]) on days 1 and 5, while the rats in the MTX + SMN group received MTX $(20 \mathrm{mg} / \mathrm{kg}$, i.p.) on days 1 and 5 and SMN $(200 \mathrm{mg} / \mathrm{kg}$, orally) for 6 weeks. Lastly, the rats in the SMN group received only SMN (200 mg/kg, orally) for 6 weeks.

\section{Histopathological examination}

At the end of the experiments, the body weight of all rats was recorded, and they were then administered $50 \mathrm{mg} / \mathrm{kg}$ ketamine and $10 \mathrm{mg} / \mathrm{kg}$ xylazine hydrochloride i.p. anesthesia. Necropsy was performed on all animals, and macroscopic changes in the testicles were recorded. Tissue samples were collected from the testicles and fixed in Boin's solution. After routine tissue follow-up, the samples were embedded in paraffin blocks; $4-\mu \mathrm{m}$ sections were taken using a microtome (Leica RM 2135), stained with hematoxylin-eosin, and examined under a light microscope (Nikon 80i-DS-RI2). Histopathological findings were graded as mild $(*)$, medium $(* *)$, and severe $(* * *)$.

\section{Immunohistochemical staining}

Immunohistochemical (IHC) examination was performed to investigate GPx1 and SOD2 expression. The streptavidin-peroxidase method ( $\mathrm{ABC}$ ) was used to stain the sections. Commercial antibodies were visualized on 5 - $\mu$ m-thick paraffin sections using an indirect streptavidin/ biotin immunoperoxidase kit (Histostain-Plus Bulk Kit; Zymed, South San Francisco, CA, USA). Tissue sections were incubated with the GPx1 (abcam-ab22604) (1:400) and SOD2 (abcam-ab13533) (1:200) primary antibodies overnight at $4{ }^{\circ} \mathrm{C}$. Finally, to visualize the reactions, the sections were reacted for 5-15 min with diaminobenzidine (DAB). After the DAB reactions developed, the sections were counterstained with hematoxylin. We used negative controls to verify the staining; these slides were reacted with PBS instead of primer antibodies. All slides were examined and photographed using a light microscope (Nikon 80i-DS-RI2). 


\section{Quantitative analysis}

Immunohistochemical staining was evaluated semiquantitatively using a double grading system, using a so-called quick score (Q), which comprised an intensity score (I) and proportional score (P). The I score reflect the intensity of positive staining in cell nuclei and cytoplasm, while the P score reflects the percentage of cell nuclei and cytoplasms with positive staining (Sagsöz, Saruhan, 2011). In this method, the intensity of staining was evaluated as follows: 0 , negative staining; 1 , weak staining; 2 , intermediate staining; 3 , strong staining. To evaluate the P score, the expression of GPx-1 and SOD2 in the testes was examined microscopically at $400 \times$ magnification. Five randomly selected areas including at least 100 cells were evaluated per section. The proportions of stained nuclei and cytoplasm of cells were recorded as follows: $0 \%, 0$; approximately $1 \%, 1 ; 1-10 \%, 2 ; 11-33 \%, 3 ; 34$ $-66 \%, 4$; and $67-100 \%, 5$. The I score was then added to the P score, which yielded the Q score, which ranged from 0 to 8 .

\section{Biochemical analysis}

After the experimental treatment, blood and postnecropsy testicular tissue samples were withdrawn from the rats for biochemical analyses. The testicle samples were studied for malondialdehyde (MDA), GPx catalase (CAT), and SOD. The level of MDA in the tissues was determined using the method described by Jain et al. (1989) based on thiobarbituric acid reactivity.

\section{Spermatological examination}

In studies on rat sperm, density is usually determined by counting epididymal or testicular sperms. Epididymal sperm can be counted by counting the sperms in the caput, corpus, cauda, or whole epididymis (Amann, Lambiase, 1969). In general, researchers most often use the method of counting epididymal sperm (Robb, Amann, Killian, 1978). In the present study, the sperm density in the caudal epididymis was examined after sperms were collected via puncture from the according to the method of Robb et al. (1978), immediately after the rats were dissected. Spermatological tests were also conducted using classic sperm testing methods.

\section{Statistical analyses}

All data were expressed as mean \pm standard deviation (SD). The statistical analyses were made using Minitab 13 for windows packet program. One way ANOVA statistical test was used to determine the differences between means of the treatments and the control group accepting the significance level at $p \leq 0.05$. The differences among the pathological changes were also determined by chi-square test.

\section{RESULTS AND DISCUSSION}

\section{Histopathological findings}

Table I shows the histopathological lesions, number of affected rats, and the severity of the alterations. No gross lesions were observed in the testis structures of rats in the control, SMN, and MTX + SMN groups. However, the testicles of the rats in the MTX group showed congested darkcolored areas at the serosa. Microscopically, the testicular sections from the control (Figure 1A) and SMN (Figure 1B) groups had normal histological appearances. In the MTX group, germ cells were dissociated from the basal membrane, and several immature germinal cell accumulations were observed in the lumen of seminiferous tubules. A widespread loss of spermatozoa was also observed in the tubular lumens. Moreover, areas of atrophy were apparent in the diameter of the tubules. Additionally, interstitial spaces were expanded with edema, and congestion and thromboses were present in the vessels. Hyperchromasia and pyknosis of the nuclei of the spermatogonia and vacuolization and degeneration of Sertoli and germ cells were also observed (Figure 1C). Alterations were also noted in the rat testicles in the MTX + SMN group, but these changes were significantly less when compared to those in the rats in the MTX group. Lesions were localized in some tubules. However, the architecture of the tubules remained intact. A small number of germinal cells were seen in the tubular lumen. The rate of tubular atrophy and degeneration of germinal cells was lower in the MTX + SMN group than the MTX group. Spermatogenic cells in the seminiferous tubules continued spermatogenesis in a manner that included spermatozoa, and fewer pathomorphological changes were seen in the spermatogonia of the MTX + SMN group than those of the MTX group. Leydig cells were in the normal histological form. The spermatids developing in the tubules had near-normal structure (Figure 1D).

\section{Immunohistochemical findings}

Table II summarizes the findings of the IHC experiments. We evaluated GPx1 immune expression 
TABLE I - Effects of MTX and SMN on the testis structure

\begin{tabular}{|c|c|c|c|c|}
\hline Changes/lesions in testis & Control & MTX & MTX+SMN & SMN \\
\hline Vacuolization in the germ and Sertoli cells & $-/ 8^{a}$ & $8 / 8^{\mathrm{b}}$ & $4 / 8^{c}$ & $-/ 8^{a}$ \\
\hline Slight & - & 1 & 2 & - \\
\hline Moderate & - & 3 & 1 & - \\
\hline Severe & - & 4 & 1 & - \\
\hline Degeneration and necrosis & $-/ 8^{a}$ & $8 / 8^{b}$ & $8 / 8^{c}$ & $-/ 8^{a}$ \\
\hline Slight & - & 1 & 4 & - \\
\hline Moderate & - & 5 & 3 & - \\
\hline Severe & - & 2 & 1 & - \\
\hline Desquamated immature germ cells & $1 / 8^{\mathrm{a}}$ & $8 / 8^{b}$ & $5 / 8^{c}$ & $2 / 8^{\mathrm{a}}$ \\
\hline Slight & 1 & 1 & 2 & 2 \\
\hline Moderate & - & 2 & 2 & - \\
\hline Severe & - & 5 & 1 & - \\
\hline Tubular atrophy & $-/ 8^{a}$ & $7 / 8^{b}$ & $4 / 8^{c}$ & $-/ 8^{a}$ \\
\hline Slight & - & 1 & 1 & - \\
\hline Moderate & - & 2 & 2 & - \\
\hline Severe & - & 4 & 1 & - \\
\hline Intertubular edema & $-/ 8^{a}$ & $7 / 8^{b}$ & $3 / 8^{c}$ & $-/ 8^{a}$ \\
\hline Slight & - & 1 & 1 & - \\
\hline Moderate & - & 3 & 1 & - \\
\hline Severe & - & 3 & 1 & - \\
\hline
\end{tabular}

The values present the number of rats showing change/number of rats examined in each treatment group. Values with different letters $(\mathrm{a}, \mathrm{b}$ and $\mathrm{c})$ in same row are significantly different $(\mathrm{P}<0.01)$, according to the Chi-Square test.

in the testicular tissue sections. No immune reaction was observed in the negative control (Figure 2A). GPx1 immunoreactivity was observed in the testicular tissue sections from all other groups. The control and SMN group sections had the most intense staining, with similar densities. Immunoreactions were observed in Leydig and germ cells but not Sertoli cells, and the immunoreactivity was more intense in the nucleus than the cytoplasm. Immunoreactions were not observed in the central vein, endothelium, or connective tissue of the vessels (Figure 2B). GPx1 expression was significantly decreased in the MTX group in comparison with the control group (Figure 2C). SMN treatment resulted increase of GPx 1 expression in the MTX + SMN group (Figure 2D).

No immune reaction of SOD2 was observed in the negative control (Figure 3A), while positive immunoreactivity was observed in the testicular tissue sections from all other groups. The control and SMN groups showed the most intense staining. Immunoreactivity was observed in the cytoplasm of germ cells and spermatids but not in the nuclei. Immunoreactions were not observed in Sertoli cells, Leydig cells, the central vein, endothelium, or connective tissue of vessels (Figure 3B). SOD2 immune expression was significantly lower in the MTX group than in the control group (Figure 3C). Treatment with SMN resulted in almost normal SOD2 immunoreactivity in the MTX + SMN group (Figure 3D).

\section{Biochemical findings}

The activities of the CAT, GPx, and SOD enzymes in the tissue samples from the testes of all groups are shown in Table III. As shown in the table, significant alterations were seen. For example, the activities of CAT and GPX were significantly lower in the MTX group than those in the control group $(p<0.05)$. Compared to the MTX group, the MTX + SMN group showed significant improvements in the activities of these enzymes in the testicular tissues.

The MDA levels in the tissue samples from the testes of all groups are shown in Figure 4. These levels were significantly higher in the MTX and MTX + SMN groups than in the control group $(p<0.05)$. However, the tissue MDA levels in the MTX + SMN group were significantly lower than those in the MTX group $(p<0.05)$. 


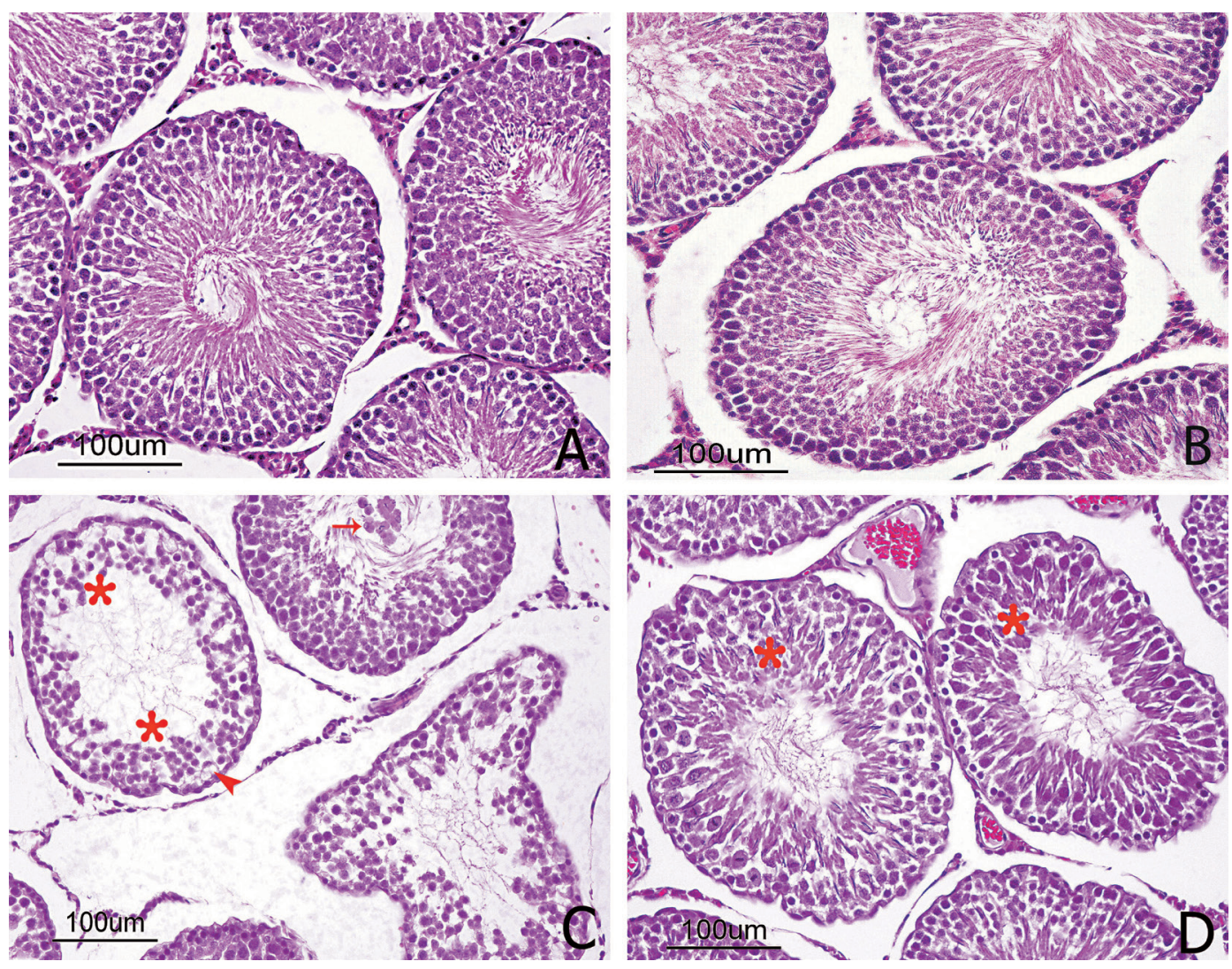

FIGURE 1 - Histopathological appearance of cross-sections of the rat testes. (A) Control and (B) SMN groups showed normal seminiferous tubule morphology and spermatogenic cells in advanced stages. Additionally, all germ cells were present and appeared normal. (C) The testes of the MTX group showed atrophy of the seminiferous tubules and arrested spermatogenesis (stars). The seminiferous tubules were irregular and had only Sertoli cells and spermatogonia. Vacuolization was apparent in the germ and Sertoli cells (arrowhead) with desquamated immature cells in the lumen of the seminiferous tubules (arrow). (D) In the testes of the MTX + SMN group, the morphology of the seminiferous tubules was almost normal. The spermatogenic cells in the seminiferous tubules (stars) continued spermatogenesis in a manner that included spermatozoa (H\&E, 200x).

TABLE II - Quick scores for GPx1 and SOD2 immun expression in testis tissue of rats

\begin{tabular}{lcccc}
\hline Parameters & Control & MTX & MTX+SMN & SMN \\
\hline GPx1 immunoreactivity of Leydig cells & $4.07 \pm 0.45^{\mathrm{a}}$ & $2.23 \pm 0.41^{\mathrm{b}}$ & $3.34 \pm 0.45^{\mathrm{c}}$ & $3.97 \pm 0.50^{\mathrm{a}}$ \\
GPx1 immunoreactivity of Germ cells & $6.27 \pm 0.81^{\mathrm{a}}$ & $3.02 \pm 0.55^{\mathrm{b}}$ & $4.38 \pm 0.38^{\mathrm{c}}$ & $6.13 \pm 0.77^{\mathrm{a}}$ \\
SOD2 immunoreactivity of Germ cells & $6.66 \pm 0.40^{\mathrm{a}}$ & $3.09 \pm 0.98^{\mathrm{b}}$ & $5.14 \pm 0.27^{\mathrm{c}}$ & $6.30 \pm 0.44^{\mathrm{a}}$ \\
\hline
\end{tabular}

Values with different letters $(\mathrm{a}, \mathrm{b}$ and $\mathrm{c})$ in same row are significantly different $(\mathrm{P}<0.05)$, according to the One way ANOVA test.

\section{Spermatological findings}

As shown in Table IV, there were significant differences in density, motility, dead-to-live sperm ratio, and abnormal sperm rate between the MTX and MTX + SMN groups in comparison with the control group $(p<$ $0.05)$.

The present study demonstrated that SMN treatment effectively protected rats against MTX-induced testicular toxicity, as evidenced by decreased MDA levels and elevated antioxidant levels. These protective effects of SMN against MTX-induced testicular toxicity were also approved by histopathological, immunohistochemical, and spermatological investigations.

In previous studies conducted to reveal the effect of MTX on testicular cells, MTX was found to decrease antioxidant activity in the cells. This made the cells vulnerable to the effects of ROS, and thereby caused damage in testicular tissues and germ cells, atrophy in seminiferous tubules, and apoptosis in germ cells (Vardi et al., 2010; 


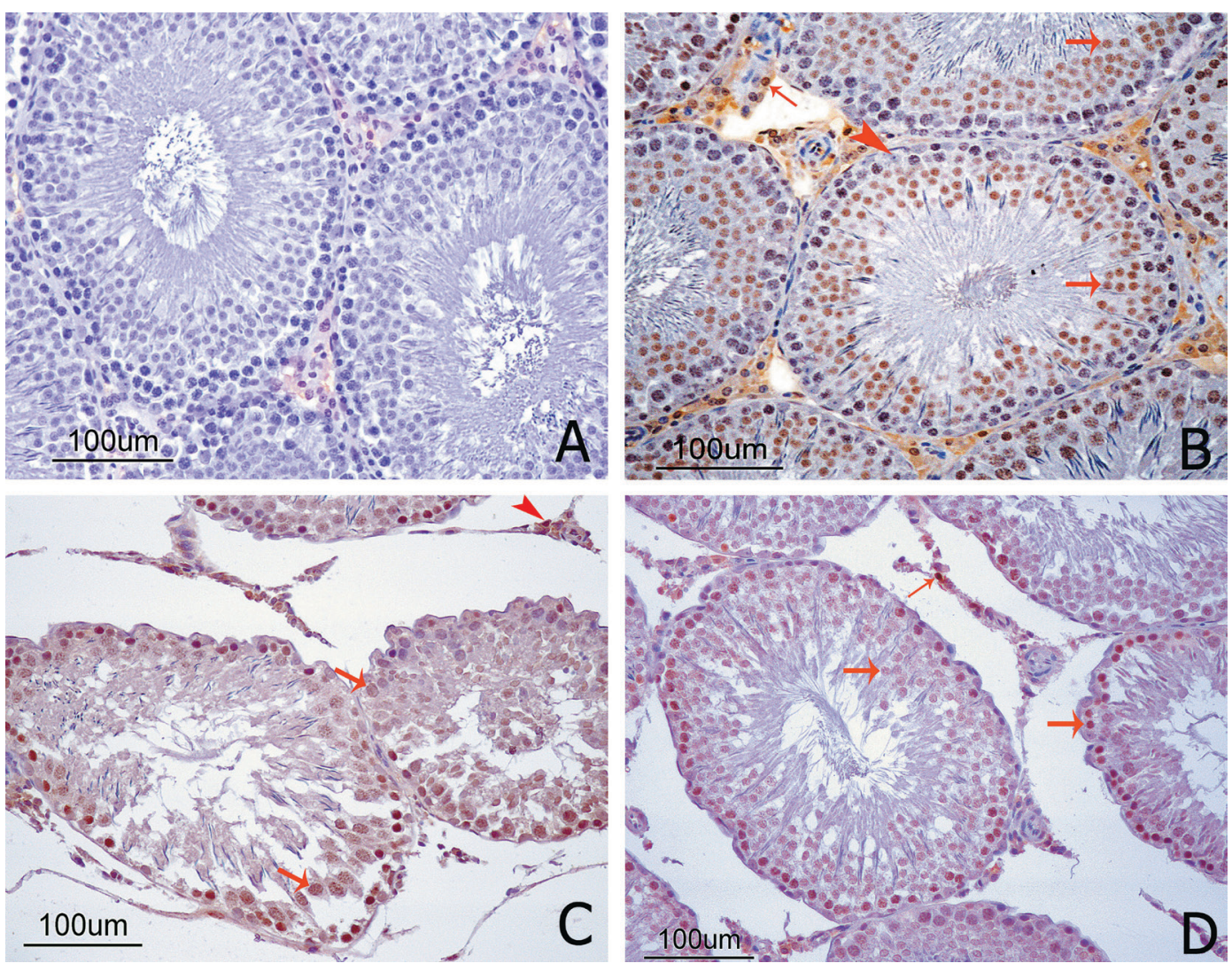

FIGURE 2 - GPx1 immunolocalization in cross-sections of the rat testes. (A) The negative control showed no GPx1 staining. (B) The control group showed strong nuclear expression of GPx1 in the germ (thick arrows) and Leydig cells (thin arrow). No staining was observed in the Sertoli cells (arrowhead). (C) The MTX group showed weak nuclear GPx1 immunoreactivity in the germ (arrows) and Leydig cells (arrowhead). (D) The MTX + SMN group showed intense nuclear GPx1 immunoreactivity in the germ (thick arrows) and Leydig (thin arrow) cells.

Padmanabhan et al., 2008). Ultimately, damage to the sperm DNA was established along with decreased testicular weight and sperm count, and increased abnormalities of the sperm head (Johnson et al., 1994). Padmanabhan et al. established morphological changes in seminiferous tubules, such as irregularities and vacuolizations, and decreases in spermatogonial cell series and spermatid counts (Padmanabhan et al., 2008). In turn, Saxena et al. (2004) reported an explicit decrease in the diameter of seminiferous tubules, sporadic thinning, irregularities in the basal membrane, expansion in the intertubular space, different sizes of primary and secondary spermatocytes and spermatids, and substantial decreases in the size of Sertoli and Leydig cells. In the current study, similar findings were detected in the MTX group. These changes were significantly reduced in the MTX + SMN treatment group. Results suggest that the damage in the testicles of the MTX group was protected with SMN in the MTX + SMN group.

In the present study, we immunohistochemically investigated whether the antioxidant enzymes GPx1 and SOD2 had a protective effect that could eliminate the free radicals forming with MTX. GPx1, which is one of the natural antioxidant defense systems against free radicals, protects lipid peroxidation by catalyzing the reduction of hydrogen peroxide (H2O2) or organic hydroperoxides to water or alcohols by using reduced glutathione (Herbette, Roeckel-Drevet, Drevet, 2007), and it protects cell membranes against oxidative damage (Czuczejko et al., 2003). SOD is one of the major antioxidant enzymes that protects the male reproductive organs against the harmful effects of ROS and it plays an important role in testicular development and spermatogenesis (Fujii et al., 2003; Prahalathan, Selvakumar, Varalakshmi, 2004). SOD2 (MnSOD) serves as a necessary defender against mitochondrial superoxide radicals (McIntyre, Bohr, Dominiczak, 2009). Previous studies have suggested that SOD2 has a ROS scavenging capacity (Nomiyama et al., 2003). Changes that take place in this enzyme may lead to impaired testicular functions and the cessation of sperm development (Prahalathan, Selvakumar, Varalakshmi, 2004).

In the present study, MTX caused a lowering of GPx1 and SOD2 immunoreactivities in testicular tissue. 

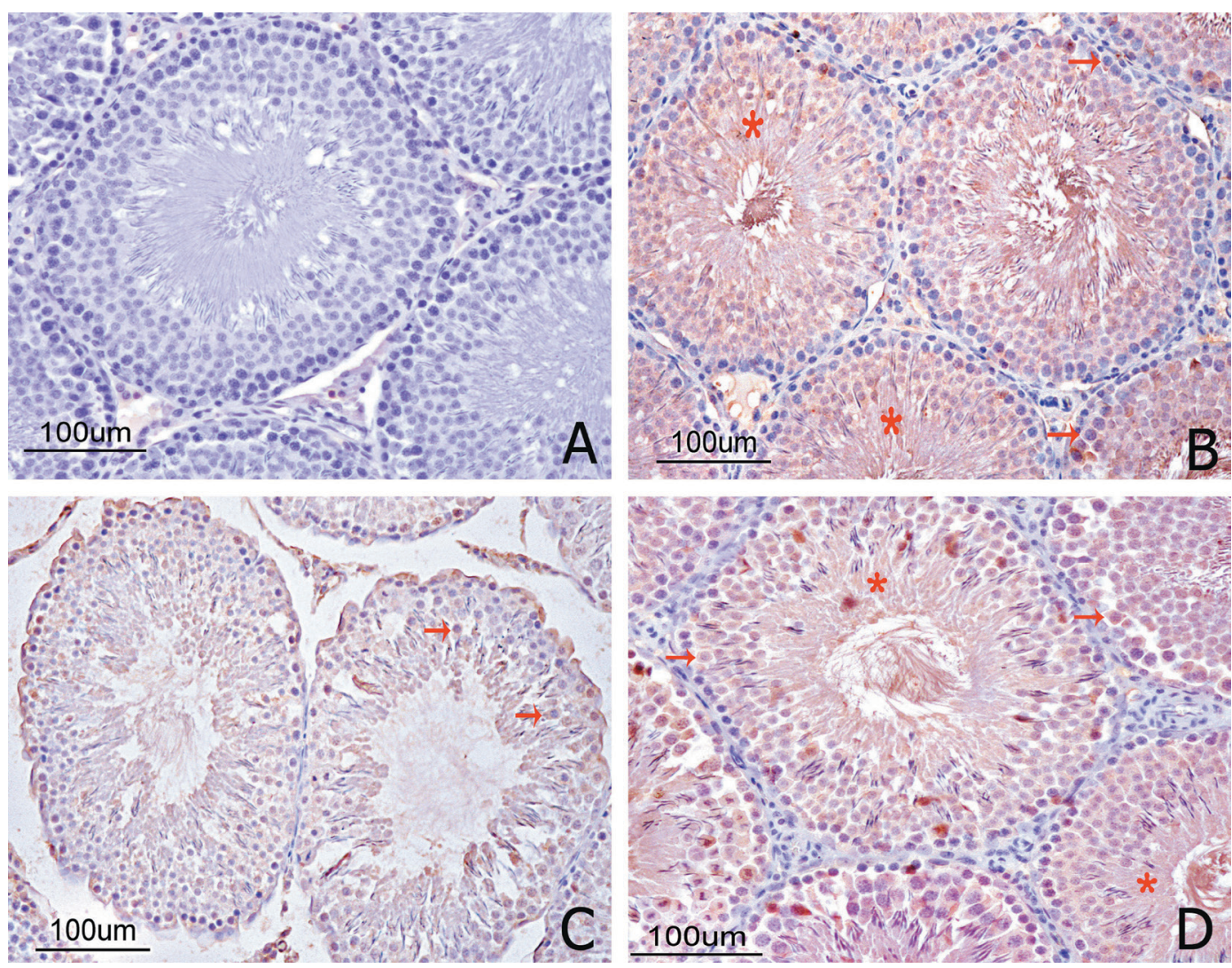

FIGURE 3 - SOD2 immunolocalization in cross-sections of rat testes. (A) The negative control showed no SOD2 staining. (B) The control group showed strong SOD2 expression in the cytoplasm of the germ (arrows) cells and spermatids (stars). No staining was observed in the Sertoli and Leydig cells. (C) The MTX group showed weak cytoplasmic SOD2 immunoreactivity in the germ cells (arrows). (D) The MTX + SMN group showed stronger cytoplasmic SOD2 immunoreactivity in the germ cells (arrows) and spermatids (stars) than the MTX group did.

However, GPx1 and SOD2 immunoreactivities in the testes of rats treated with SMN increased significantly compared to the MTX group. Immunohistochemical results were consistent with the biochemical results. Increased activities of these enzymes are known to serve as protective enzymes for the elimination of reactive free radicals (Cheung et al., 2011)

It has been reported that MTX could cause a reduction in levels of GPx, SOD, and CAT in testis tissue (Vardi et al., 2010; Yulug et al., 2013). In the present study, the decreased levels in the MTX group were compatible with the findings of previous studies. On the other hand, the activities of these enzymes in the MTX + SMN group were comparable with those of the control group. The observation that the application of SMN caused the GPx and CAT levels to increase to their normal levels in the MTX + SMN-treated group indicates that the testes were restored to their normal activity by the protective effect of SMN.

Malondialdehyde (MDA) is widely used as an indicator of lipid peroxidation (Esterbauer et al., 1982). Increased MDA levels might have resulted from an increase in ROS as a result of an oxidative stress condition (Yaman, Yener, Celik, 2016). Also, an increased MDA level is a significant indicator of oxidative membrane damage (Freeman, Crapo, 1981). Increased oxidative stress with MTX has been reported to result in the production of ROS, which causes oxidative damage by decreasing Nicotinamide adenine dinucleotide phosphate (NADPH) and increasing MDA (Vardi et al., 2010). In the present study, treatment with SMN significantly decreased the MDA contents in the MTX + SMN group. This result indicates the restorative effects of SMN on the MDA levels of testis tissue.

The protective effect of SMN treatment may be due to its protection of cellular membranes against oxidative damage (Nencini, Giorgi, Micheli, 2007). Such antioxidant effects of SMN can be explained by the presence of bioactive chemical components present in SMN, such as flavolignans, silydianin, silychristin, and silybin (Farghali et al., 2000).

The chemotherapeutic agent most commonly studied on laboratory animals in terms of the gonadal 


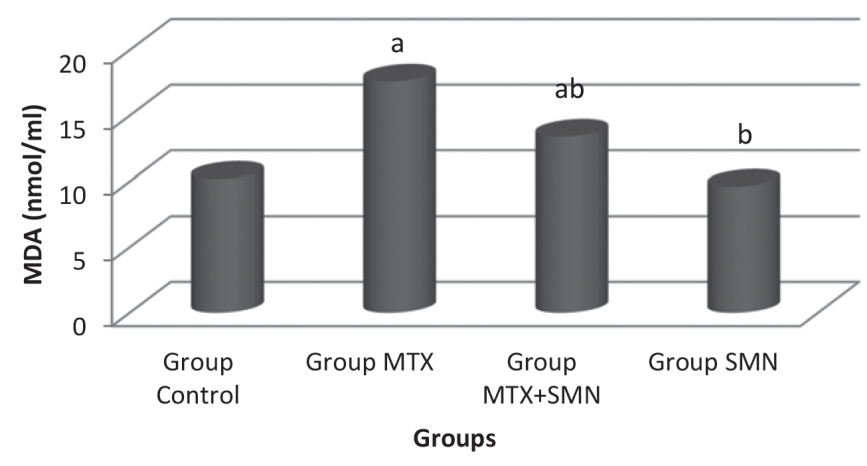

a: significantly different from control group, ${ }^{\mathrm{b}}$ : significantly different from MTX group rats at $\mathrm{p}<0.05$ (One way ANOVA).

FIGURE 4 - Effects of MTX and SMN on MDA levels in testis tissue of rats.

toxicity of anti-metabolites is MTX. Due to its damages to the spermatogenic cells, MTX is reported as one of the agents that can cause infertility (Vardi et al., 2010). The testicular damage related to the MTX-induced oxidative stress occurs directly in the spermatogenic cells and Sertoli cells, and leads to dysfunction of Leydig cells and therefore, reduced testosterone levels. It was reported that low and moderate doses of MTX cause oligospermia in rats, but do not lead to testicular atrophy (Johnson et al.,
1994). On the other hand, studies with MTX on rat testicles found decreases in testicular weight, (Vardi et al., 2010), fatal effects on all spermatogenic cells, particularly on spermatocytes and spermatids and reducing effects on the size of Sertoli and Leydig cells (Saxena et al., 2004). Furthermore, the findings of cytogenetic studies on mice suggest that MTX leads to varying degrees of chromosomal aberrations, DNA damage, and apoptosis in germ cells; decreases in epididymal sperm count and motility, and increases in abnormal sperm rates (Padmanabhan et al., 2008). In the presented study, there were significant differences $(p<0.05)$ in density, motility, dead-live sperm rate and abnormal sperm rate in the MTX group rats compared to MTX + SMN and control group. It was seen that such effect occurred only in the MTX group due to the damage in the testicles, and was not observed in the MTX + SMN group due to the protective effect of SMN.

\section{CONCLUSION}

We conclude that SMN appears to have a protective role in MTX-induced testicular toxicity as it enhances the activities of antioxidant enzymes, decreases MDA levels, and protects spermatogenesis. We think this protective effect of SMN may be due to its antioxidant activity. Therefore,

TABLE III - Effects of MTX and SMN on antioxidant defense systems in testis tissue of rats

\begin{tabular}{lcccc}
\hline \multirow{2}{*}{ Parameters } & \multicolumn{4}{c}{ Experimental groups } \\
\cline { 2 - 5 } & Control & MTX & MTX+SMN & SMN \\
\hline CAT U/g & $82.16 \pm 8.21$ & $47.75 \pm 9.18^{\mathrm{a}}$ & $63.36 \pm 5.53^{\mathrm{ab}}$ & $89.18 \pm 8.79^{\mathrm{b}}$ \\
GPx U/g & $85.32 \pm 10.02$ & $46.52 \pm 11.42^{\mathrm{a}}$ & $59.49 \pm 8.33^{\mathrm{ab}}$ & $79.74 \pm 15.12^{\mathrm{b}}$ \\
SOD U/g & $1982.19 \pm 48.84$ & $2047.72 \pm 62.43$ & $1972.14 \pm 83.19$ & $2086.16 \pm 56.83$ \\
\hline
\end{tabular}

Each value represents the Mean \pm SD. ${ }^{\text {a }}$ : significantly different from control group ${ }^{\text {b: }}$ significantly different from MTX group at $p<0.05$ (One way ANOVA).

TABLE IV - Effects of MTX and SMN on Spermatological data by study groups

\begin{tabular}{lcccc}
\hline Parameters & Control & MTX & MTX+SMN & SMN \\
\hline Sperm concentration $\left(\times 10^{9} / \mathrm{ml}\right)$ & $4.02 \pm 0.38^{\mathrm{a}}$ & $1.14 \pm 0.52^{\mathrm{b}}$ & $2.92 \pm 0.25^{\mathrm{c}}$ & $3.93 \pm 1.03^{\mathrm{a}}$ \\
Sperm motility (\%) & $78.14 \pm 4.05^{\mathrm{a}}$ & $8.12 \pm 4.36^{\mathrm{b}}$ & $56.41 \pm 2.17^{\mathrm{c}}$ & $75.43 \pm 4.73^{\mathrm{a}}$ \\
Dead live (\%) & $7.11 \pm 2.15^{\mathrm{a}}$ & $64.27 \pm 4.25^{\mathrm{b}}$ & $26.45 \pm 6.91^{\mathrm{c}}$ & $9.15 \pm 1.24^{\mathrm{a}}$ \\
Abnormal sperm rate (\%) & $10.17^{\mathrm{a}}$ & $95.55^{\mathrm{b}}$ & $38.65^{\mathrm{c}}$ & $9.85^{\mathrm{a}}$ \\
Head abnormality (\%) & $3.03^{\mathrm{a}}$ & $27.26^{\mathrm{b}}$ & $17.05^{\mathrm{c}}$ & $2.75^{\mathrm{a}}$ \\
Acrosome abnormality (\%) & $0.5^{\mathrm{a}}$ & $8.33^{\mathrm{b}}$ & $5.69^{\mathrm{c}}$ & $0.5^{\mathrm{a}}$ \\
Mid piece abnormality (\%) & $2.18^{\mathrm{a}}$ & $6.49^{\mathrm{b}}$ & $3.75^{\mathrm{c}}$ & $1.89^{\mathrm{a}}$ \\
Tail abnormality (\%) & $3.34^{\mathrm{a}}$ & $12.58^{\mathrm{b}}$ & $6.71^{\mathrm{c}}$ & $3.28^{\mathrm{b}}$ \\
\hline
\end{tabular}

Values with different letters $(\mathrm{a}, \mathrm{b}$ and $\mathrm{c})$ in same row are significantly different $(\mathrm{P}<0.05)$, according to the One way ANOVA test. 
SMN can be used in clinical practice for preventing side effects that can occur in testicles due to MTX use. However, this study needs to be supported with other experimental and clinical research to understand the underlying mechanisms responsible for changing the balance between the oxidative processes and antioxidant defense systems.

\section{REFERENCES}

Amann RP, Lambiase JT. The male rabbit. III. Determination of Daily sperm production by means of testicular homogenates. J Anim Sci. 1969;28(3):369-374.

Armagan A, Uzar E, Uz E, Yilmaz HR, Kutluhan S, Koyuncuoglu HR, Soyupek S, Cam H, Serel TA. Caffeic acid phenethyl ester modulates methotrexate-induced oxidative stress in testes of rat. Hum Exp Toxicol. 2008;27(7):547-552.

Asci H, Ozer MK. Protective effect of misoprostol in methotrexate induced liver and kidney damage. SDÜ J Health Sci. 2011;2(2):125-126.

Atessahin A, Şahna E, Türk G. Chemoprotective effect of melatonin against cisplatin-induced testicular toxicity in rats. J Pineal Res. 2006;41(1):21-27.

Bükücü NK. Effects of vitamin E and L-carnitine against methotrexate- induced injury in rat testis. Gaziantep University, Thesis of Master Science, Gaziantep; 2013.

Cheung CCC, Zheng GJ, Li AMY, Richardson BJ, Lam PKS. Relationships between tissue concentrations of polycyclic aromatic hydrocarbons and antioxidative responses of marine mussels, Perna viridis. Aquat Toxicol. 2011;52(3):189-203.

Czuczejko J, Zachara BA, Staubach-Topczewska E, Halota W, Kedziora J. Selenium, glutathione and glutathione peroxidases in blood of patients with chronic liver diseases. Acta Biochim Pol. 2003;50(4):1147-1154.

Esterbauer H, Cheeseman KH, Dianzani MU, Poli G, Slater TF. Separation and characterization of the aldehydic products of lipid-peroxidation stimulated by Adp-Fe2+ in rat-liver microsomes. Biochem J. 1982;208(1):129-140.

Farghali H, Kamenikova L, Hynie S, Kmonickova E. Silymarin effects on intracellular calcuim and cytotoxicity: a study in perfused rat hepatocytes after oxidative stress injury. Pharmacol Res. 2000;41(2):231-237.
Freeman BA, Crapo JD. Hyperoxia increases oxygen radical production in rat lungs and lung mitochondria. J Biol Chem. 1981;256(21):10986-10992.

Fujii J, Iuchi Y, Matsuki S, Ishii T. Cooperative function of antioxidant and redox systems against oxidative stress inmale reproductive tissues. Asian J Androl. 2003;5(3):231-242.

Gogus F. Methotrexate and osteopathy. Arch Rheumatol. 2001;16(1):52-57.

Halliwell B. How to characterize an antioxidant: an update. Biochem Soc Symp. 1995;61:73-101.

Herbette S, Roeckel-Drevet P, Drevet JR. Seleno-independent glutathione peroxidases. More than simple antioxidant scavengers. FEBS J. 2007;274(9):2163-2180.

Jain SK, McVie R, Duett J, Herbst JJ. Erythrocyte membrane lipid peroxidation and glycolylated hemoglobin in diabetes. Diabetes. 1989;38(12):1539-1543.

Johnson FE, Farr SA, Mawad M, Woo YCS. Testicular cytotoxicity of intravenous methotrexate in rats. J Surg Oncol. 1994;55(3):175-178.

McIntyre M, Bohr DF, Dominiczak AF. Endothelial function in hypertension: the role of superoxide anion. Hypertension. 1999;34:539-45.

Morris LF, Harrod MJ, Menter MA, Silverman AK. Methotrexate and reproduction in men: case report and recommendations. $\mathrm{J}$ Am Acad Dermatol. 1993;29(5):913-916.

Moshtaghion SM, Malekinejad H, Razi M, Shafie-Irannejad V. Silymarin protects from varicocele-induced damages in testis and improves sperm quality: evidence for E2f1 involvement. Syst Biol Reprod Med. 2013;59(5):270-280.

Muslimovic A, Nyström S, Gao Y, Hammarsten O. Numerical analysis of etoposide induced DNA breaks. PLoS One. 2009;10(4):e5859.

Nencini C, Giorgi G, Micheli L. Protective effect of silymarin on oxidative stress in rat brain. Phytomedicine. 2007;14(2):129-135.

Nomiyama T, Tanaka Y, Piao L, Nagasaka K, Sakai K, Ogihara T, Nakajima K, Watada H, Kawamori R. The polymorphism of manganese superoxide dismutase is associated with diabetic nephropathy in Japanese type 2 diabetic patients. J Hum Genet. 2003;48(3):138-141. 
Padmanabhan S, Tripathi DN, Vikram A, Ramarao P, Jena GB. Cytotoxic and genotoxic effects of methotrexate in germ cells of male swiss mice. Mutat Res. 2008;655(1):59-67.

Padmanabhan S, Tripathi DN, Vikram A, Ramarao P, Jena GB. Methotrexate-induced cytotoxicity and genotoxicity in germ cells of mice: intervention of folic and folinic acid. Mutat Res. 2009;673(1):43-52.

Prahalathan C, Selvakumar E, Varalakshmi P. Remedial effect of DL- $\alpha$-lipoic acid against adriamycin induced testicular lipid peroxidation. Mol Cell Biochem. 2004;267(1):209-214.

Rašković A, Stilinović N, Kolarović J, Vasović V, Vukmirović $\mathrm{S}$, Mikov M. The protective effects of silymarin against doxorubicin-induced cardiotoxicity and hepatotoxicity in rats. Molecules. 2011;16(10):8601-8613.

Robb GW, Amann RP, Killian GJ. Daily sperm production and epididymal reserves of pubertal and adult rats. J Reprod Fertil. 1978;54(1):103-107.

Sagsöz H, Saruhan BG. The expression of vascular endothelial growth factor and its receptors (flt1/fms, flk1/KDR, flt4) and vascular endothelial growth inhibitor in the bovine uterus during the sexual cycle and their correlation with serum sex steroids. Theriogenology. 2011;75(9):1720-1734.

Sargin AK, Emin EO, Can B, Saran Y. 2009. Fare böbreğinde metotraksatın oluşturduğu morfolojik değişiklikler. AUJST-A. 2009;10(1):197-203.

Saxena AK, Dhungel S, Bhattacharya S, Jha CB, Srivastava AK. Effect of chronic low dose of methotrexate on cellular proliferation during spermatogenesis in rats. Arch Androl. 2004;50(1):33-35.

Sayilmaz A. Methotreksat toxicity caused histopatological changes in rat testis to investigate the effect of vitamin $\mathrm{C}$. Thesis of Master Scince, Necmettin Erbakan University, Konya; 2015.
Thomson AB, Campbell AJ, Irvine DC, Anderson RA, Kelnar CJ, Wallace WH. Semen quality and spermatozoal DNA integrity in survivors of childhood cancer: a case-control study. Lancet. 2012;360(9330):361-367.

Uyar A, Yener Z, Dogan A. Protective effects of Urtica dioica seed extract in aflatoxicosis: histopathological and biochemical findings. Brit Poultry Sci. 2016;57(2):235-245.

Valavanidis A, Vlahogianni T, Dassenakis M, Scoullos M Molecular biomarkers of oxidative stress in aquatic organisms in relation to toxic environmental pollutants. Ecotoxicol Environ Saf. 2006;64(2):178-189.

Vardi N, Parlakpınar H, Ateş B, Otlu A. The preventive effects of chlorogenic acid against to testicular damage caused by methotrexate. Türkiye Klinikleri J Med Sci. 2010;30(2):507513.

Vardi N, Parlakpinar H, Ates B, Cetin A, Otlu A. Antiapoptotic and antioxidant effects of $\beta$-carotene against methotrexateinduced testicular injury. Int J Fertil Steril. 2009;92(6):20282033.

Vardi N, Parlakpinar H, Ozturk F, Ates B, Gul M, Cetin A, Erdogan A, Otlu A. Potent protective effect of apricot and b-carotene on methotrexate-induced intestinal oxidative damage in rats. Food Chem Toxicol. 2008:46(9):3015-3022.

Yaman T, Yener Z, Celik I. Histopathological and biochemical investigations of protective role of honey in rats with experimental aflatoxicosis. BMC Compl Alter Med. 2016;16:232.

Yuluğ E, Türedi S, Alver A, Türedi S, Kahraman C. Effects of resveratrol on methotrexate-induced testicular damage in rats. Sci World J. 2013;2013:489659.

Received for publication on $29^{\text {th }}$ August 2017 Accepted for publication on $02^{\text {nd }}$ November 2017 